\title{
A Density-Functional Theory Structural Database for Discovery of Novel Actinide Waste Forms
}

Matthew S. Christian ${ }^{\dagger \S}$, Kristen A. Pace ${ }^{\dagger \ddagger}$, Vladislav V. Klepov ${ }^{\ddagger}$, Gregory Morrison ${ }^{\dagger \ddagger}$, HansConrad zur Loye ${ }^{\dagger *}$, and Theodore M. Besmann ${ }^{\dagger *}$

†Center for Hierarchical Waste form Materials, Columbia, South Carolina 29208, United States

*Department of Chemistry and Biochemistry, University of South Carolina, Columbia, South Carolina 29208, United States

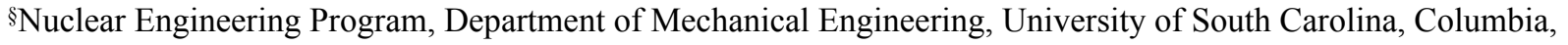
South Carolina 29208, United States currently at Department of Chemistry, Northwestern University, Evanston, IL, 60208, United States

Figure 1: DOS plots for the three least stable combination of structural motif, actinide and alkali. These DOS plots show that a bandgap is present.

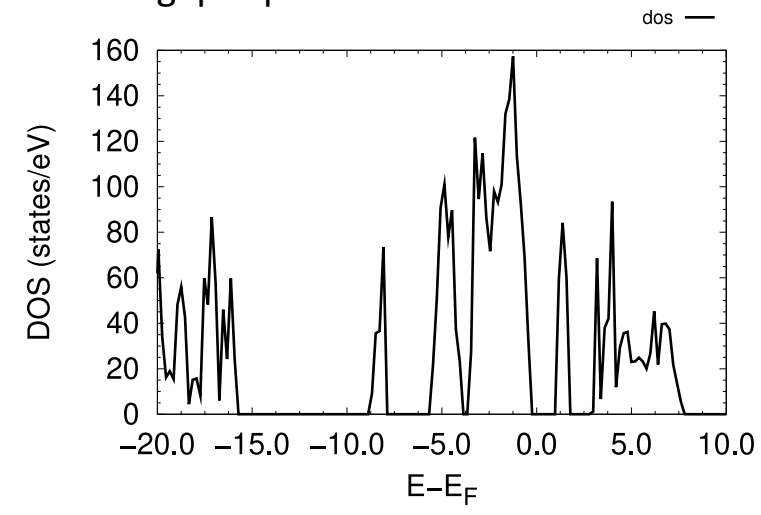

(a) $\mathrm{Na}_{2} \mathrm{Pu}\left(\mathrm{AsO}_{4}\right)_{2} \mathrm{P1}$

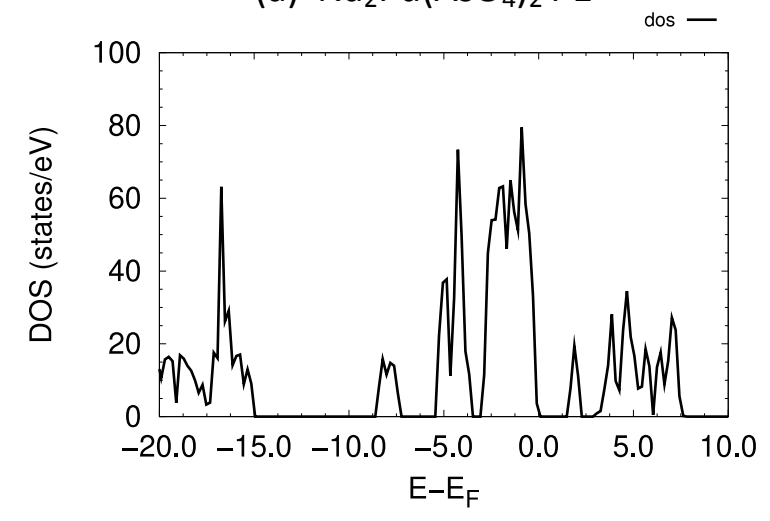

(b) $\mathrm{Na}_{2} \mathrm{Pu}\left(\mathrm{AsO}_{4}\right)_{2}$ i41a 


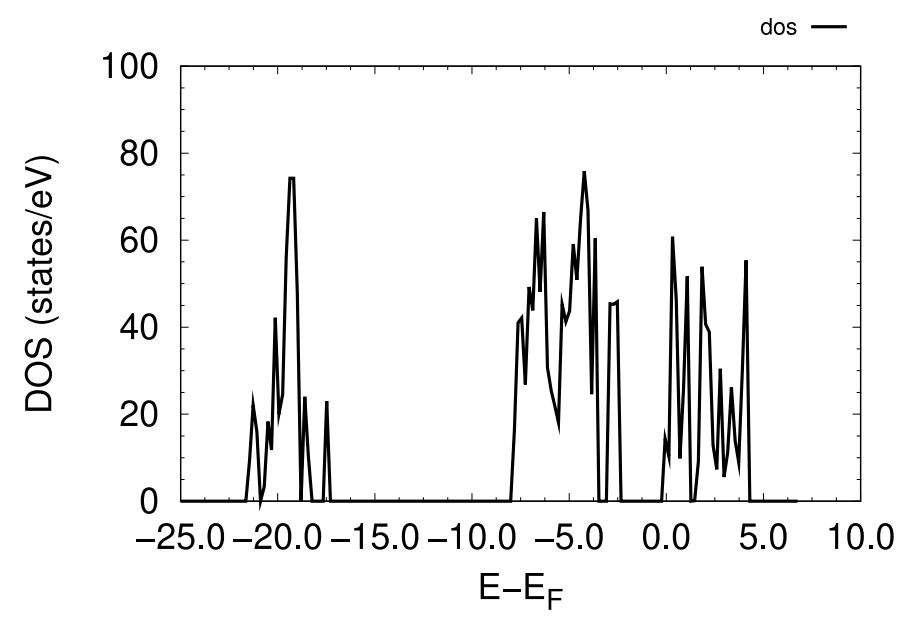

(c) $\mathrm{Na}_{2} \mathrm{Pu}\left(\mathrm{MoO}_{4}\right)_{2} \mathrm{P} 1$

Figure 2: DOS of the three most stable combination of structural motif, actinide and alkali, which have filled of partially filled bands near the Fermi energy, indicating that delocalization error is causing the compounds to be incorrectly modeled and likely over-stabilized.

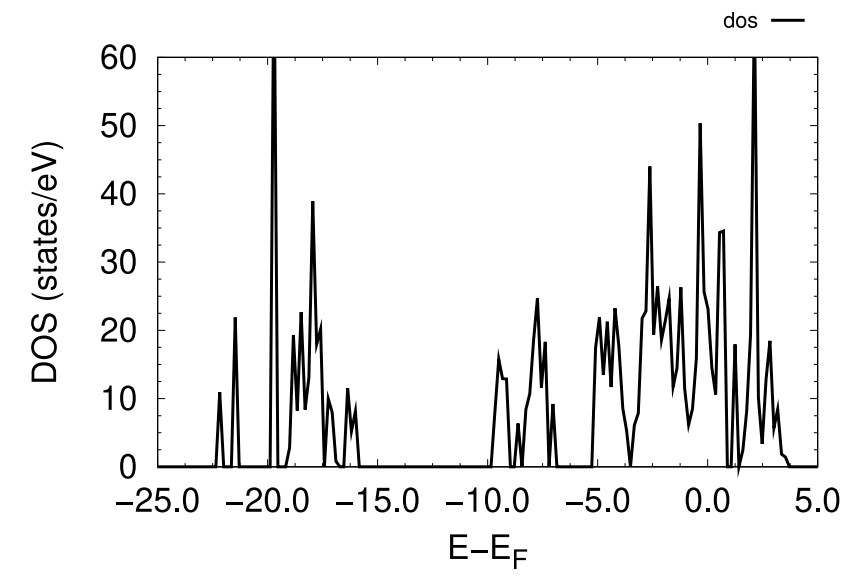

(a) $\mathrm{Cs}_{2} \mathrm{U}\left(\mathrm{PO}_{4}\right)_{2} \mathrm{Fddd}$

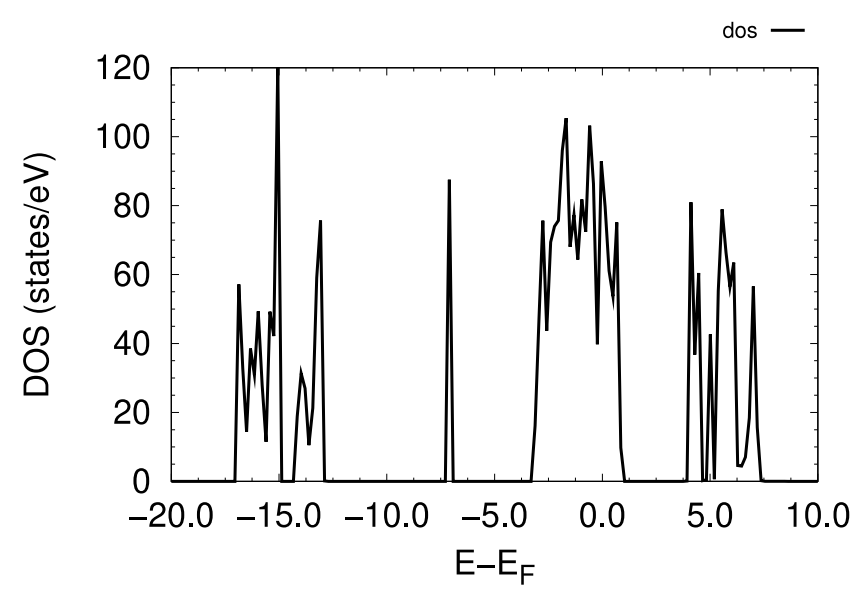

(b) $\mathrm{RbTh}_{2}\left(\mathrm{PO}_{4}\right)_{3} \mathrm{C} 2 \mathrm{c}$ 


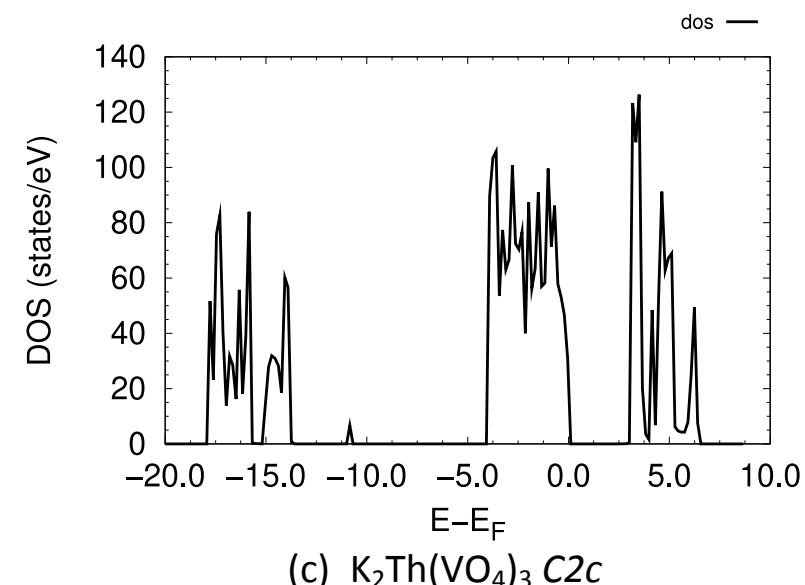

